\title{
RESEARCH ON USE OF LOW CONCENTRATION INVERSE SOLUBILITY POLYMERS IN WATER FOR HARDENING MACHINE COMPONENTS AND TOOLS
}

\author{
Nikolai Kobasko \\ Intensive Technologies Ltd \\ 68/1 Peremohy ave., Kyiv, Ukraine, 03113 \\ nkobasko@gmail.com \\ Anatolii Moskalenko \\ Institute of Engineering Thermophysics of NASU \\ 2 A Zhelyabova str., Kyiv, Ukraine, 03057 \\ an.moskalenko@gmail.com \\ Volodymyr Dobryvechir \\ Intensive Technologies Ltd \\ 68/1 Peremohy ave., Kyiv, Ukraine, 03113 \\ dobrivecher@yahoo.com
}

\begin{abstract}
There is an optimal water concentration of inverse solubility polymers $(1 \%)$ where in many cases film boiling is absent. Based on accurate experimental data of French and data of authors, it was shown that during quenching from 875 oC in cold water solutions of optimal concentration film boiling is completely absent for those steel parts initial heat flux densities of which are below critical value. It is established that initial heat flux density decreases with increase sizes of tested samples. Initial process of quenching (formation of boundary boiling layer), which makes further history of cooling, is not investigated deeply and widely yet enough. When film boiling is absent, mathematical model includes only transient nucleate boiling process and convection. In this case, cooling time within the transient nucleate boiling process can be calculated using average effective Kondratjev numbers Kn. They were evaluated for inverse solubility polymers depending on their concentration and sizes of tested samples. As a result, an improved technology of hardening large gears and bearing rings is proposed by authors. Its essence consists in interruption of accelerated cooling or turning off agitation of quenchant when dissolving of surface polymeric layer starts. Examples of performing improved technology are provided by authors. Developments can be used by engineers to switch from carburized large gears quenched in oil to gears made of optimal hardenability steel and quenched in water solutions of optimal concentration.

Keywords: polymers of inverse solubility, optimal concentration, initial heat flux, boiling process, effective Kn numbers, recipes, large gears, improved technology.
\end{abstract}

\section{Introduction}

As a rule, water polymers are widely used in the practice as a quenchant of medium and high concentration $(5 \%, 10 \%, 20 \%$, and rarely $30 \%)$ to compete with mineral and vegetable oils. Cooling process is performed like in oil which continues almost to bath temperature. Standard cooling curves and cooling rates characteristics of water polymers are provided by manufactures to maintain polymeric quenchants within the given requirements. Cooling curves and cooling rates data cannot be used for making calculations and developing recipes. As a result, in heat treating industry sometimes a big distortion is observed after quenching machine components in water polymer solutions. Author [1] explained such behavior by non-uniform dissolving surface polymeric layer when quenching in water polymer solution of inverse solubility. Moreover, a long ago authors [2, 3] came to conclusion that low water concentration of inverse solubility polymers $(\approx 1 \%)$ provides maximal cooling rate of standard probes and this important fact in not yet used in the practice to intensify quenching processes. The goal of this paper is research concerning low concentration of water polymers solutions of inverse solubility for hardening machine components and tools like large gears of wind power stations, large bearing rings, rollers, etc. A method of calculation is dis- 
cussed to prevent non-uniform dissolving of polymeric surface layer which can be performed by interruption the process of cooling or turning off the quenchant agitation. The results of investigations can be used by engineers for improving quality of hardened machine components and tools.

\section{Initial and critical heat flux densities}

To predict film boiling present during quenching steel parts or probes in liquids, one should compare initial heat flux density $\left(\mathrm{q}_{\mathrm{in}}\right)$ with critical heat flux density $\left(\mathrm{q}_{\mathrm{cr}}\right)$. If initial heat flux density is below the first critical heat flux density $\mathrm{q}_{\text {crl }}$, film boiling is absent [4-6]. If it accedes $\mathrm{q}_{\mathrm{crl}}$, full film boiling takes place. It should be noted that initial processes taking place during immersion heated steel parts into cold liquid are not investigated yet. The cooling process starts as follows:

- At the very beginning steel parts or probes have initial temperature $\mathrm{T}_{0}\left(850^{\circ} \mathrm{C}\right)$ and quenchants have a temperature $20^{\circ} \mathrm{C}$.

- Within the time interval $\mathrm{T}_{0}$-A (Fig. 1) the double electrical layer is formed when quenching in electrolytes or insulating surface layer is created when quenching in water solutions of inverse solubility polymers.

- When quenching in agitated water salt solution of optimal concentration, the time interval $\mathrm{T}_{0}-\mathrm{A}$ is almost the same for different sizes and forms of steel parts.

- Within the time interval $\mathrm{T}_{0}-\mathrm{A}$ the liquid of boundary layers is heated above of its boiling point to develop transient nucleate boiling process which starts at point $A$.

- Within the time interval $\mathrm{T}_{0}-\mathrm{A}$ hyperbolic heat conductivity equation preferably should be used for calculating temperature field and initial heat flux density in steel parts or probes.

- After transient nucleate boiling starts, conventional parabolic heat conductivity (1) with the boundary condition (2) can be used.

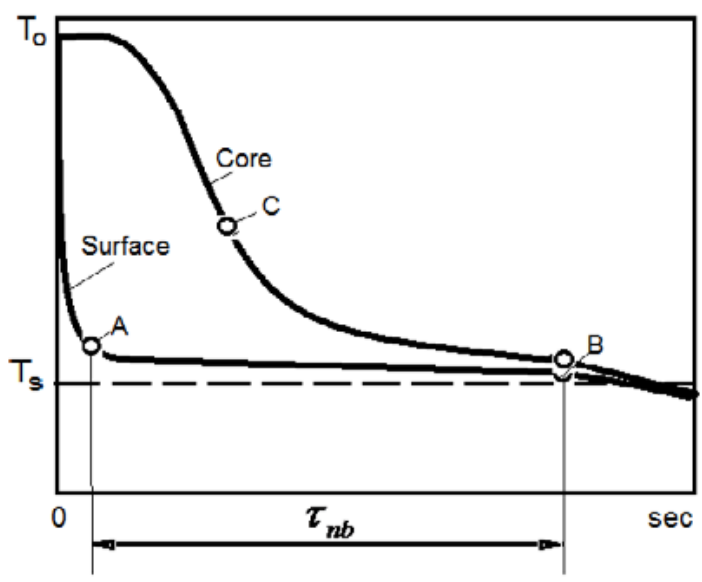

Fig. 1. A scheme explaining cooling time calculation during transient nucleate boiling process:

$\mathrm{T}_{0}$ is initial austenitzing temperature; $\mathrm{A}$ is initial surface temperature of developed transient nucleate boiling process; $\mathrm{B}$ is finish surface temperature of boiling process; $\mathrm{C}$ is core temperature of product for which cooling time should be calculated within interval $\mathrm{AB}$; $\mathrm{T}_{\mathrm{s}}$ is saturation temperature; $\tau_{\mathrm{nb}}$ is duration of transient nucleate boiling process

To be sure that film boiling during quenching can be absent, authors calculated initial heat flux densities using own experimental data and experimental data of French shown in Table 1 [7]. For solving inverse problem IQLab software was used [8]. More information on inverse problem one can find in literature [9-11]. Material thermal properties of probes are provided in Table 2. The main issue was to find out how size of probe affects initial heat flux density because standard probes are small and real steel parts are large. The results of calculations are shown in Fig. 2, $\boldsymbol{a}, \boldsymbol{b}$.

When quenching spherical probe $12.7 \mathrm{~mm}$ in diameter from $875{ }^{\circ} \mathrm{C}$ in $5 \%$ water solution of $\mathrm{NaOH}$ at $20^{\circ} \mathrm{C}$ agitated with $0.914 \mathrm{~m} / \mathrm{s}$ initial heat flux density is $17 \mathrm{MW} / \mathrm{m}^{2}$ that is below $\mathrm{q}_{\mathrm{crl}}$ for given concentration and agitation. It means that film boiling is absent. With increase the size of probe, initial 
heat flux decreases (Fig. 2, b). It means that film boiling can be easily prevented for large steel parts. However, large steel part during quenching in liquid increases its average temperature that decreases critical heat flux density and by this way increases probability of existing film boiling. To prevent heating of quenchant, its volume should be appropriate and liquid should be agitated.

Table 1

Time required for the surface of steel spheres of different sizes to cool to different temperatures when quenched from $875{ }^{\circ} \mathrm{C}$ in $5 \%$ water solution of $\mathrm{NaOH}$ at $20{ }^{\circ} \mathrm{C}$ agitated with $0.914 \mathrm{~m} / \mathrm{s}$ (French, 1930)

\begin{tabular}{|c|c|c|c|c|c|c|c|c|}
\hline \multirow{2}{*}{$\begin{array}{l}\text { Size, Inches, } \\
\quad(\mathrm{mm})\end{array}$} & \multicolumn{8}{|c|}{ Time, sec } \\
\hline & $700{ }^{\circ} \mathrm{C}$ & $600{ }^{\circ} \mathrm{C}$ & $500{ }^{\circ} \mathrm{C}$ & $400{ }^{\circ} \mathrm{C}$ & $300{ }^{\circ} \mathrm{C}$ & $250{ }^{\circ} \mathrm{C}$ & $200^{\circ} \mathrm{C}$ & $150{ }^{\circ} \mathrm{C}$ \\
\hline $\begin{array}{c}0.5 " \\
(12.7)\end{array}$ & 0.028 & 0.042 & 0.058 & 0.071 & 0.11 & 0.15 & 0.26 & 0.60 \\
\hline $\begin{array}{c}4.75 ” \\
(120.6)\end{array}$ & 0.043 & 0.066 & 0.09 & 0.12 & 0.17 & 0.21 & 0.29 & 0.95 \\
\hline $\begin{array}{c}7.15 ” \\
(181.6)\end{array}$ & 0.040 & 0.070 & 0.100 & 0.140 & 0.240 & 0.310 & 0.42 & 1.15 \\
\hline $\begin{array}{l}11.25 " \\
(285.8)\end{array}$ & 0.043 & 0.120 & 0.190 & 0.330 & 0.570 & 0.960 & 1.26 & 2.18 \\
\hline
\end{tabular}

Table 2

Thermal properties (diffusivity and conductivity) of Inconel 600 and stainless steel depending on temperature in ${ }^{\circ} \mathrm{C}$

\begin{tabular}{ccccc}
\hline \multirow{2}{*}{ Temperature, ${ }^{\circ} \mathbf{C}$} & \multicolumn{2}{c}{ Inconel 600 } & \multicolumn{2}{c}{ Stainless steel AISI 304 } \\
\cline { 2 - 5 } & $\mathrm{a} \times 10^{-6}, \mathrm{~m}^{2} / \mathrm{s}$ & $\lambda, \mathrm{W} / \mathrm{mK}$ & $\mathrm{a} \times 10^{-6}, \mathrm{~m}^{2} / \mathrm{s}$ & $\lambda, \mathrm{W} / \mathrm{mK}$ \\
\hline 100 & 3.7 & 14.2 & 4.55 & 17.5 \\
200 & 4.1 & 16 & 4.63 & 18 \\
250 & 4.3 & 16.9 & 4.66 & 18.8 \\
300 & 4.5 & 17.8 & 4.7 & 21 \\
400 & 4.8 & 19.7 & 4.95 & 23 \\
500 & 5.1 & 21.7 & 5.34 & 24.8 \\
600 & 5.4 & 23.7 & 5.65 & 26.3 \\
700 & 5.6 & 25.9 & 5.83 & 6.19 \\
800 & 5.8 & 26.3 & 6.55 & 27.8 \\
900 & 6.0 & 28 & & 29.3
\end{tabular}

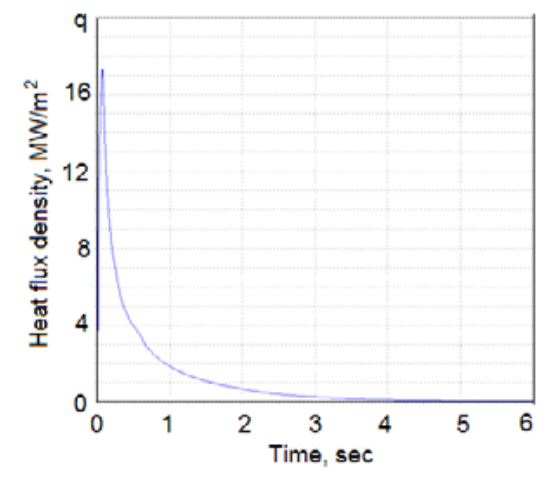

$a$

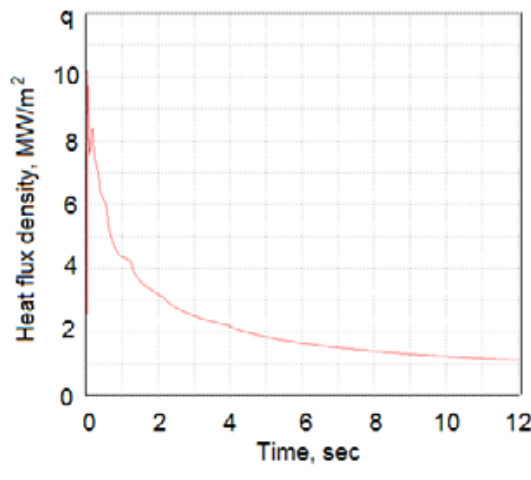

$b$

Fig. 2. Heat flux density versus time when quenching spherical steel samples in $5 \%$ water $\mathrm{NaOH}$ solution at $20^{\circ} \mathrm{C}$ agitated with $0.914 \mathrm{~m} / \mathrm{s}: a-12.7 \mathrm{~mm}$ in diameter; $b-286 \mathrm{~mm}$ in diameter 
According to investigations [4], very fast cooling increases critical heat flux density and it prevails the initial heat flux density that eliminates completely film boiling process.

\section{Optimal concentration of inverse solubility polymers in water}

As seen from Fig. 3, there is an optimal concentration of inverse solubility polymer in water where probability of destroying vapor blanker is maximal. This optimal concentration combined with agitation of quenchant can completely prevent film boiling during hardening.

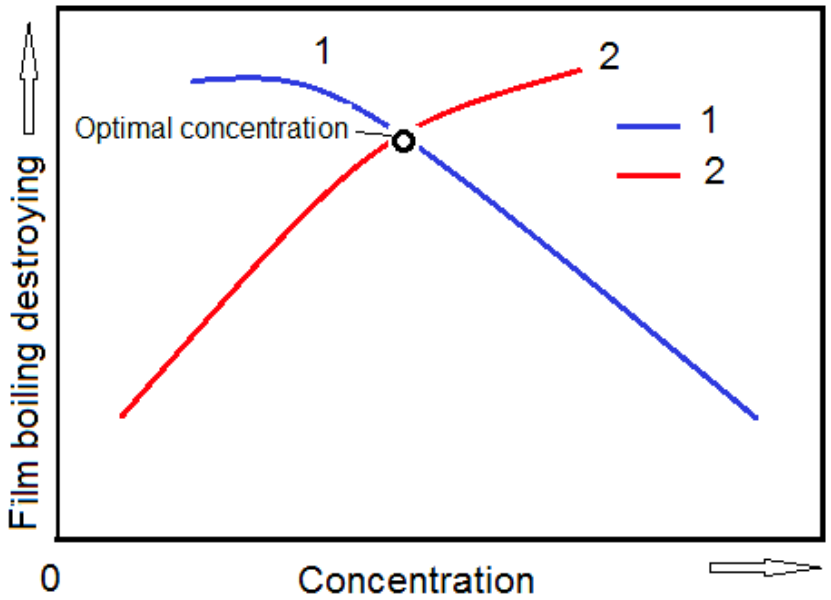

Fig. 3. Probability of film boiling destroying with decreasing the first critical heat flux density (curve 1) and formation of the surface insulating layer (curve 2) versus concentration of inverse solubility polymer in water

Our experiments showed that optimal concentration of inverse solubility polymers in water can be rather low (about $1 \%$ ) that makes a bath quenchant less expensive.

\section{Cooling time calculation during quenching in polymers}

If the film boiling process is absent and the transient nucleate boiling takes place immediately, the cooling process is governed by the following equations (1)-(6), [12-14]:

$$
\begin{gathered}
\operatorname{c\rho } \frac{\partial \mathrm{T}}{\partial \tau}=\operatorname{div}(\lambda \operatorname{grad} \mathrm{T}), \\
{\left[\frac{\partial \mathrm{T}}{\partial \mathrm{r}}+\frac{\beta^{\mathrm{m}}}{\lambda}\left(\mathrm{T}-\mathrm{T}_{\mathrm{S}}\right)^{\mathrm{m}}\right]_{\mathrm{r}=\mathrm{R}}=0,} \\
\mathrm{~T}(\mathrm{r}, 0)=\mathrm{T}_{0} .
\end{gathered}
$$

After transient boiling process is completed, a convection mode of heat transfer starts and the third kind of boundary condition (4) is used instead of boundary condition (2):

$$
\left[\frac{\partial \mathrm{T}}{\partial \mathrm{r}}+\frac{\alpha_{\mathrm{conv}}}{\lambda}\left(\mathrm{T}-\mathrm{T}_{\mathrm{m}}\right)\right]_{\mathrm{r}=\mathrm{R}}=0 .
$$

The initial temperature for the convection mode is the temperature distribution at the end of the transient nucleate boiling process:

$$
\mathrm{T}(\mathrm{r}, 0)=\mathrm{T}\left(\mathrm{r}, \tau_{\text {conv }}\right)
$$


It means that

$$
\mathrm{T}\left(\mathrm{r}, \tau_{\mathrm{nb}}{ }^{\text {end }}\right)=\mathrm{T}\left(\mathrm{r}, \tau_{\text {conv }}{ }^{\text {start }}\right)
$$

and it's chosen as an initial condition for the convection mode.

A transition from the nucleate boiling process to the convective mode of heat transfer is determined by equalizing the heat fluxes and the end of boiling and at the beginning of convection (6), i. e.

$$
\mathrm{q}_{\mathrm{nb}} \equiv \mathrm{q}_{\text {conv }} .
$$

A generalized equation for calculating duration of the transient nucleate boiling process, based on solution of Eq. (1)-(3), was proposed [15]:

$$
\tau_{\mathrm{nb}}=\Omega \mathrm{k}_{\mathrm{F}} \frac{\mathrm{D}^{2}}{\mathrm{a}}
$$

The value of $\Omega$ is a function of the convective Biot number.

According to author [1, 15], an average effective Kondratjev number Kn can be find which allows calculating cooling time within the transient boiling nucleate boiling process using simple Eq. (8):

$$
\frac{\mathrm{a} \tau}{\mathrm{K}}=\frac{0.24 \mathrm{k}+\ln \theta}{\mathrm{Kn}}
$$

Fig. 4 provides average effective Kondratjev numbers Kn for inverse solubility polymers of different concentrations.

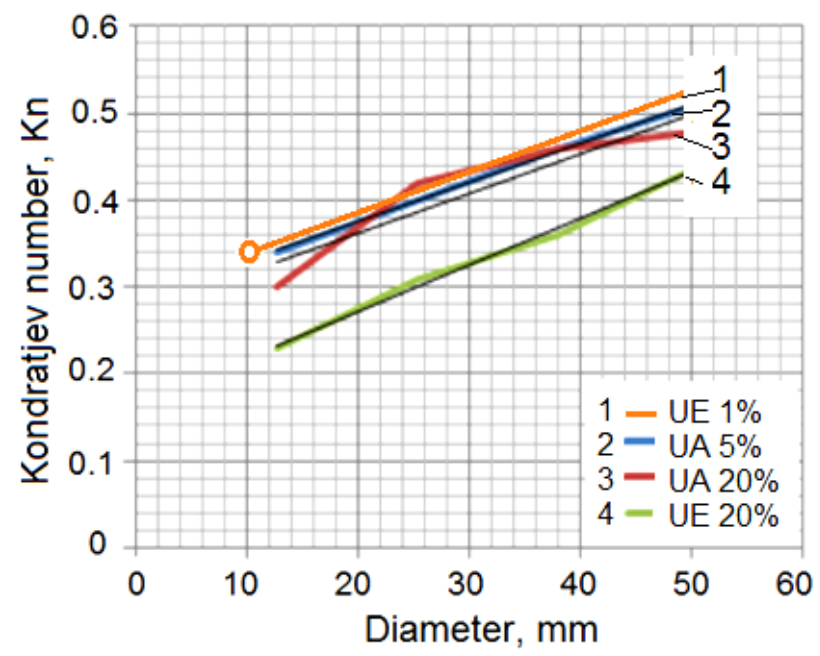

Fig. 4. Effective Kondrtjev numbers Kn for inverse solubility water solutions of polymers depending on their concentrations and size of product: 1 is $1 \%$ of UCON E in water; 2 is $5 \%$ of

UCON A in water; 3 is $20 \%$ of UCON A in water; 4 is $20 \%$ of UCON E in water at $20^{\circ} \mathrm{C}$

New results in Fig. 4 are data concerning $1 \%$ UCON E in water at $20{ }^{\circ} \mathrm{C}$ depending on size of probes changing from $10 \mathrm{~mm}$ to $50 \mathrm{~mm}$ in thickness.

Obtained data from Fig. 4 and Kondratjev form coefficients K from Table 3 allow calculating cooling recipes when quenching steel parts in water solutions of inverse solubility polymers. Principal scheme of quenching process is shown in Fig. 5. 
Table 3

Kondratjev coefficients $\mathrm{K}$ depending on different shapes and sizes of solid bodies [16]

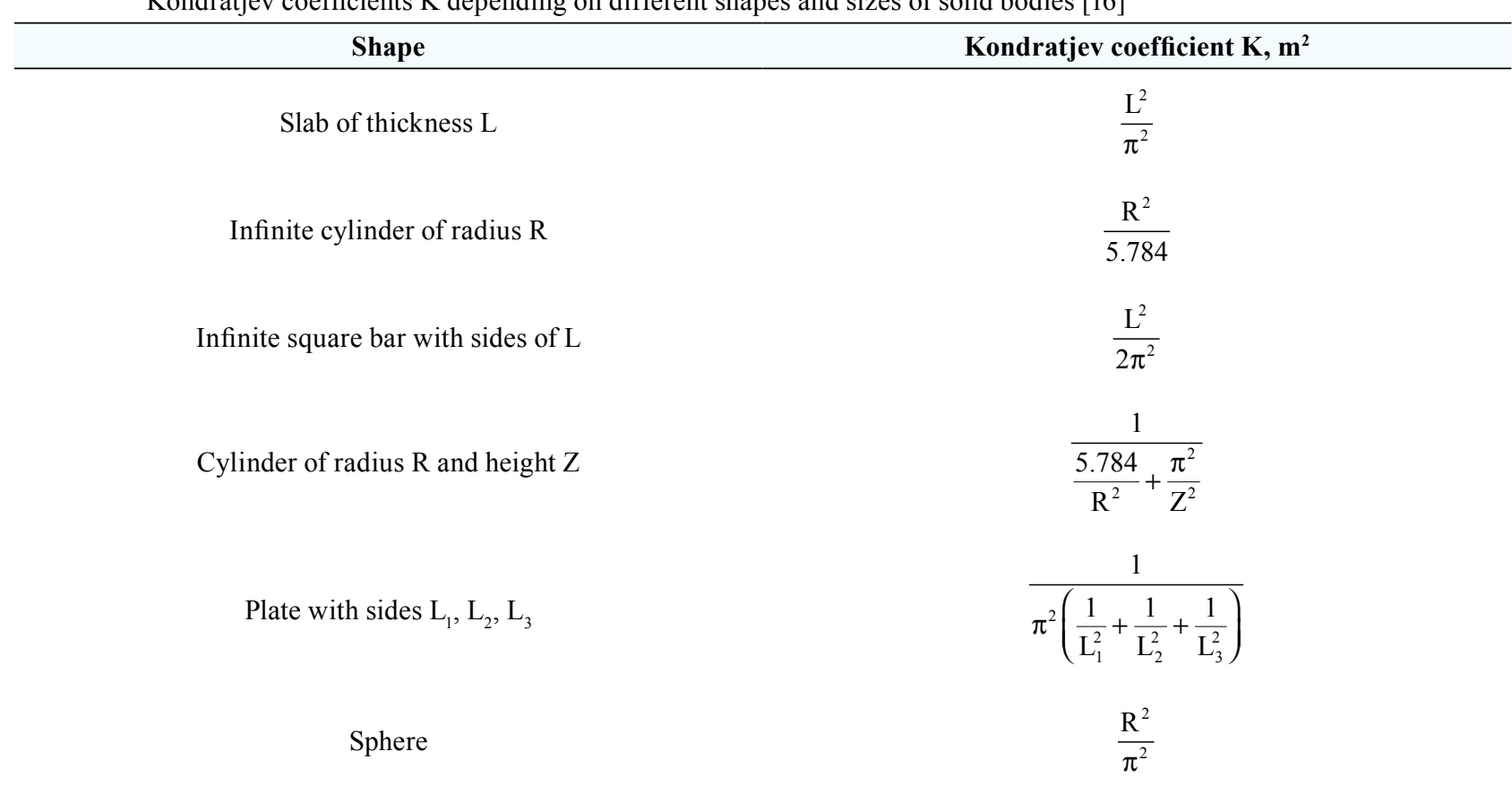

Note: $R$ is radius, $L$ is thickness, $Z$ is height

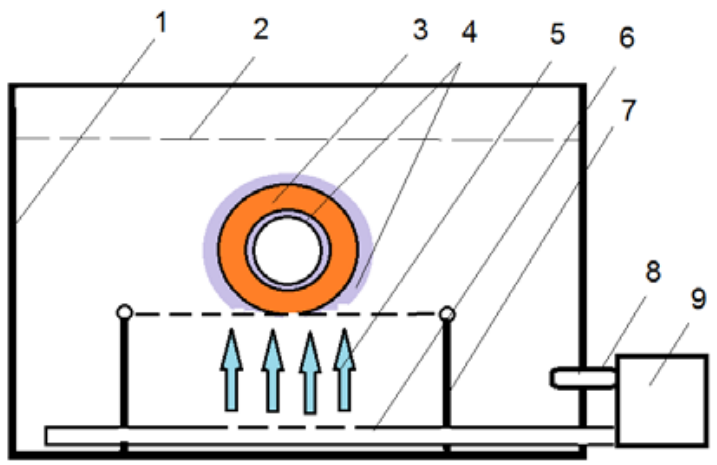

Fig. 5. Prinsipal scheme of performing IQ -2 process with use of low concentration polymers: 1 is quench tank; 2 is level quenchant in a tank; 3 is steel parft (large gear or large bearing ring); 4 is surface polymeric layer; 5 is liquid stream; 6 is perforated tube; 7 is holder; 8 is outlet tube;

9 is pump

\section{An example}

A large ring $40 \mathrm{~mm}$ in thickness and $120 \mathrm{~mm}$ height, made of AISI 52100 steel, is quenched from $860{ }^{\circ} \mathrm{C}$ in $1 \%$ water solution of inverse solubility polymer agitated with $0.5 \mathrm{~m} / \mathrm{s}$ (Fig. 5). To prevent dissolving surface polymeric layer which causes distortion of a ring, cooling should be interrupted when core temperature approaches $400{ }^{\circ} \mathrm{C}$. For calculating cooling time Eq. (8) is used.

Initial data: $\mathrm{k}=1$;

$$
\begin{gathered}
\mathrm{K}=\frac{1}{\frac{9.87}{0.04^{2}}+\frac{9.87}{0.12^{2}}}=145.7 \times 10^{-6} \mathrm{~m}^{2}(\text { Table 3)} ; \\
\mathrm{a}=5.36 \times 10^{-6} \mathrm{~m}^{2} / \mathrm{s} ;
\end{gathered}
$$




$$
\begin{gathered}
\mathrm{Kn}=0.48 \text { (Fig. 4); } \\
\operatorname{Ln} \theta=\operatorname{Ln} \frac{860{ }^{\circ} \mathrm{C}-20{ }^{\circ} \mathrm{C}}{400{ }^{\circ} \mathrm{C}-20{ }^{\circ} \mathrm{C}}=0.793 .
\end{gathered}
$$

According to Eq. (8) interruption cooling time is:

$$
\tau=(0.24+0.783) \times \frac{145.7 \times 10^{-6} \mathrm{~m}^{2}}{5.36 \times 10^{-6} \mathrm{~m}^{2} / \mathrm{s} \times 0.48}=58 \mathrm{~s} .
$$

\section{Discussion}

At present time wind power stations (wind mills) are working worldwide to provide the potential economic, environmental, and social benefits. In the USA plan is to supply by wind mills $10 \%$ of the nation's electrical demand in $2020,20 \%$ in 2030 , and $35 \%$ in 2050 . The main attention is paid to reducing the cost of electricity, and accelerating the deployment of wind power. The typical wind power station (wind mill) containing large gears is shown in Fig. 6 [22].

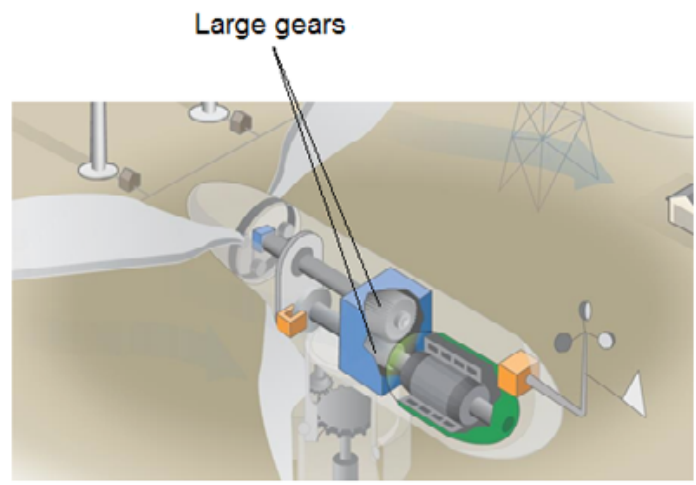

Fig. 6. Typical wind mill station containing large gears [22]

That is why decreasing cost of large gears and increasing their service life is very important. Authors of the paper are proposing to manufacture large gears from alloy low hardenability steel [23] and quench them in agitated $1 \%$ water solution of inverse solubility polymers to eliminate carburizing process, improve resistance against corrosion and increase service life of large gears. Further work in this field is needed to investigate properly initial hardening processes including crisis of boiling to provide correctly boundary condition for hyperbolic heat conductivity equations used for governing initial quenching processes [24-26]. Also, extremely important is problem concerning protection gears from corrosion [27]. Authors believe that tendency to corrosion of gears will decrease if carburizing process is eliminated.

However, accelerated hardening of complicated steel parts requires control of cooling process and its interruption at proper time that is possible when process is automated and special software for developed technology is available. Currently, the problem is being solved by Intensive Technologies Ltd (ITL), Kyiv, Ukraine.

\section{Conclusions}

1. There is an optimal low concentration $(\approx 1 \%)$ of inverse solubility polymers in water where film boiling is absent.

2. During quenching machine components and tools in optimal concentration of inverse solubility polymers, film boiling is completely absent due to initial heat flux density is below critical value caused by creation of the surface insulating layer.

3. When diameter of spherical probe increases from $12.7 \mathrm{~mm}$ to $286 \mathrm{~mm}$, initial heat flux density during quenching in electrolytes decreases from $17.2 \mathrm{MW} / \mathrm{m}^{2}$ to $10.2 \mathrm{MW} / \mathrm{m}^{2}$. That simplifies preventing film boiling process during quenching large steel parts in water solution of poly- 
mers due to increased size of real steel parts and presence on their surfaces insulating layer that decreases initial heat flux density.

4. Low concentration of inverse solubility polymers can be used as a perfect quenchant for hardening large steel parts like large bearing rings, large gears for wind power stations, rollers, etc.

5. Accelerated quenching in water solutions of polymers should be interrupted before polymeric surface layer at the bottom of a load is dissolved that prevents quench crack formation and decreases cardinally distortion. For this purpose IQCalc2 software can be used which is available from Intensive Technologies Ltd, Kyiv, Ukraine.

6. To perform correctly cooling time interruptions, authors experimentally evaluated effective dimensionless Kondratjev numbers Kn for polymers of inverse solubility depending on their concentration and size of machine components (Fig. 4).

7. In contrast to existing cooling curves and cooling rates data provided by manufactures, authors of the paper proposed simplified method of cooling time calculation in water solutions of polymers to decrease distortion and increase service life of hardened machine components in two or more times [13].

8. Further investigations in the field are needed; especially initial process of quenching requires careful investigations to study critical heat flux densities and mechanism of surface polymeric layer formation.

\section{References}

[1] Kobasko, N. (2017). Cooling intensity of inverse solubility polyalkylene glykol polymers and some results of investigations focused on minimizing distortion of metal components. EUREKA: Physics and Engineering, 2, 55-62. doi: 10.21303/2461-4262.2017.00294

[2] Kobasko, N. I., Moskalenko, A. A. (1996). Intensification the methods of quenching by means of use water polymer solutions. Promyshlennaya Teplotekhnika, 18 (6), 55-60.

[3] Moskalenko, A. A., Kobasko, N. I., Tolmacheva, O. V., Totten, G. E., Webster, G. M. (1996). Quechants Characterization by Acoustical Noise Analysis of Cooling Properties of Aqueous Poly (Alkylene Glycol) Polymer Quenchants. Proceedings of the Second International Conference on Quenching and Control of the Distortion. Cleveland: Cleveland Marriott Society Center, 117-122.

[4] Tolubinsky, V. I. (1980). Teploobmen pri kipenii [Heat transfer at boiling]. Kyiv: Naukova Dumka, 320.

[5] Kutateladze, S. S. (1963). Fundamentals of Heat Transfer. New York: Academic Press, 485.

[6] Kutateladze, S. S. (1950). Hydrodynamic Crisis Model of Heat Transfer in Boiling Liquid at Free Convection. Journal of Engineering Physics, 20 (11), 1389-1392.

[7] French, H. J. (1930). The Quenching of Steels. Cleveland: American Society for Steel Treating, 177.

[8] Kobasko, N. I., Dobryvechir, V. V. (2010). Inverse Problems in Quench Process Design. Intensive Quenching Systems: Engineering and Design. West Conshohocken: ASTM International USA, $210-229$.

[9] Tikhonov, A. N., Glasko, V. B. (1967). On the Issue of Methods of Determination of the Part's Surface Temperature. Journal of Computational Mathematics and Mathematical Physics, 7 (4), 910-914.

[10] Alifanov, O. M. (1975). Outer Inverse Heat Conduction Problems. Eng. Phys. Jour., 29 (1), 13-25.

[11] Beck, J. V., Osman, A. M. (1992). Analysis of Quenching and Heat Treating Processes Using Inverse Heat Transfer Method. Proceedings of Quenching and Distortion Control Conference. Chicago: ASM International, 147-154.

[12] Lykov, A. V. (1967). Teoriya Teploprovodnosti [Theory of Heat Conductivity]. Moscow: Vyschaya Shkola, 596.

[13] Kobasko, N. I., Aronov, M. A., Powell, J. A., Totten, G. E. (2010). Intensive Quenching Systems: Engineering and Design. West Conshohocken, ASTM International, 234. doi: 10.1520/mnl64-eb

[14] Guseynov, Sh. E., Buikis, A., Kobasko, N. I. (2006). Mathematical statement of a problem with the hyperbolic heat transfer equation for the intensive steel quenching processes and its analytical solution. Equipment and Technologies for Heat Treatment of Metals and Alloys (OTTOM-7). Kharkov, 2, 22-27. 
[15] Kobasko, N. I. (2009). Transient Nucleate Boiling as a Law of Nature and a Basis for Designing of IQ Technologies. Proc. of the 7th IASME/WSEAS International Conference on Heat Transfer, Thermal Engineering and Environment (HTE'09). Moscow, 67-76.

[16] Kondratev, G. M. (1957). Teplovye Izmereniya [Thermal Measurements]. Moscow: Mashgiz, 245 .

[17] Liscic, B., Tensi, H. M., Luty, W. (Eds.) (1992). Theory and Technology of Quenching. Berlin, Heidelberg: Springer, 484. doi: 10.1007/978-3-662-01596-4

[18] Liscic, B., Tensi, H., Canale, L., Totten, G. (Eds.) (2010). Quenching Theory and Technology. Boca Raton: CRC Press, 725. doi: 10.1201/9781420009163

[19] Dossett, J. I., Totten, G. E. (Eds.) (2013). ASM Handbook. Vol. 4A: Steel Heat Treating Fundamentals and Processes. ASM International, 784.

[20] Totten, G. E., Bates, C. E., Clinton, M. A. (1993). Handbook of Quenchants and Quenching Technology. Ohio: ASM International, Materials Park, 507.

[21] Totten, G., Howes, M., Inouer, T. (Eds.) (2002). Handbook of Residual Stress and Deformation of Steel. Ohio: ASM International, Materials Park, 499.

[22] How do Wind Turbines Work. A New Era for Wind Power in the United States. Wind Energy Technologies Office. Available at: https://www.energy.gov/eere/wind/how-do-wind-turbines-work

[23] Kobasko, N. I. (2017). Pat. 114174 UA. Alloyed Low Hardenability Steel and Method of its Designing. MPK C22C 38/40, C22C 38/12, C21D 1/18, C22C 38/24, C22C 38/08, C22C 38/46, C21D 9/00. No. a 2013 11311; declareted: 23.09.2013; published: 10.05.2017, Bul. No. 9.

[24] Liscic, B. (2003). Critical Heat-Flux Densities, Quenching Intensity and Heat Extraction Dynamics During Quenching in Vaporizable Liquids. Proceedings of the 4th International Conference on Quenching and the Control of Distortion. Beijing, 21-28.

[25] Buikis, A. (2009). Some new models and their solutions for intensive steel quenching. Daugavpils, 27-30.

[26] Buikis, A., Buike, M., Vilums, R. (2017). Several Intensive Steel Quenching and Wave Power Models. WSEAS transactions on heat and mass transfer, 12, 107-121.

[27] Hermann, S., Holm, A.-P. (2009). Protecting Gears in Wind Power Applications. Available at: http://gearsolutions.com/article/detail/5882/protecting-gears-in-wind-power-applications 